\title{
Role of science and judgment in setting national ambient air quality standards: how low is low enough?
}

\author{
Roger O. McClellan
}

Received: 15 March 2011 / Accepted: 22 May 2011 / Published online: 1 June 2011

(C) The Author(s) 2011. This article is published with open access at Springerlink.com

\begin{abstract}
The Clean Air Act (CAA) requires listing as criteria air pollutants those pollutants that arise from multiple sources and are found across the United States. The original list included carbon monoxide, nitrogen oxides, sulfur oxides, particulate matter, photochemical oxidants (later regulated as ozone), and hydrocarbons. Later, the listing of hydrocarbons was revoked and lead was listed. The CAA requires the EPA Administrator to set National Ambient Air Quality Standards (NAAQS) for these pollutants using the "latest scientific knowledge" at levels that, in the judgment of the Administrator, are "requisite to protect public health" while "allowing an adequate margin of safety" without considering the cost of implementing the NAAQS. The NAAQS are set using scientific knowledge to inform the Administrator's policy judgments on each NAAQS. Recently, there has been increasing tension and debate over the role of scientific knowledge versus policy judgment in the setting of NAAQS. This paper reviews key elements of this debate drawing on the opinion of Supreme Court Justice Stephen Breyer, in Whitman v. American Trucking Associations, to resolve the conundrum posed by the CAA language. I conclude that scientists should carefully distinguish between their interpretations of scientific knowledge on
\end{abstract}

This paper was presented in the concluding plenary session on "Regulatory and Policy Implications" at the "American Association for Aerosol Research International Specialty Conference: Air Pollution and Health: Bridging the Gap from Sources to Health Outcomes," March 22-26, 2010, San Diego, CA.

R. O. McClellan $(\bowtie)$

Toxicology and Human Health Risk Analysis,

13701 Quaking Aspen Pl NE,

Albuquerque, NM 87111, USA

e-mail: roger.o.mcclellan@att.net specific pollutants and their personal preferences as to a given policy outcome (i.e., specific level and form of the NAAQS), recognizing that these are policy judgments as to acceptable levels of risk if the science does not identify a threshold level below which there are no identifiable health risks. These policy judgments are exclusively delegated by the CAA to the EPA Administrator who needs to articulate the basis for their policy judgments on the level and form of the NAAQS and associated level of acceptable risk.

Keywords Clean Air Act · Criteria pollutants · Ozone · Particulate matter $\cdot$ Policy $\cdot$ Risk $\cdot$ Regulations

\section{Introduction}

In this paper, I briefly review key aspects of the Clean Air Act (1970) with regard to the setting of National Ambient Air Quality Standards (NAAQS) for criteria pollutants noting various landmark decisions. I address the primary or health-based Standards and do not consider the secondary or welfare-based Standards, although the core concepts are also relevant to the setting of the secondary Standards. I highlight actions of the last two EPA Administrators (Stephen Johnson and Lisa Jackson) and the Clean Air Scientific Advisory Committee (CASAC) related to the setting of NAAQS for particulate matter and ozone that serve to illustrate the growing tension and debate over the role of scientific knowledge and policy judgments in the setting of NAAQS. I conclude with recommendations for the role of CASAC in synthesizing and interpreting the science on criteria pollutants and offering scientific advice that informs the EPA Administrator's policy judgments on acceptable health risks that, in turn, are linked to the level and statistical form of the NAAQS primary Standard. 


\section{The Clean Air Act}

The Clean Air Act (CAA), initially passed in 1963, is the principal national statute in the United States concerned with air quality. The original CAA (1963) directed the then Department of Health, Education and Welfare (HEW) to prepare, "compile and publish criteria on the effects of air pollutants," hence the identification of "criteria pollutants" and "criteria documents" summarizing the scientific knowledge on certain air pollutants arising from multiple sources and found across the United States as a basis for Standard setting. The National Air Pollution Control Administration (NAPCA) within HEW was assigned responsibility for administering the CAA. When the U.S. Environmental Protection Agency (EPA) was created in 1970, responsibility for administering the CAA was transferred from NAPCA to the new agency. Bachmann (2007) provides an in-depth review of the evolution of Air Quality Management in the United States from 1900 through 2006, with emphasis on the NAAQS, for those readers interested in an in-depth coverage of the topic. John Bachmann prepared his historical review soon after he retired from EPA's Office of Air Quality Planning and Standards where he had a central role for more than three decades in the setting of NAAQS for all the criteria pollutants. Readers interested in legal details of the CAA will find the summary of Martineau and Novello (2004) useful.

In 1970, amendments to the CAA (1970) were passed that required the listing of air pollutants that "may reasonably be anticipated to endanger public health and welfare" and to issue air quality criteria for them. These air quality criteria are to "accurately reflect the latest scientific knowledge useful in indicating the kind and extent of all identifiable effects on public health or welfare which may be expected from the presence of [a] pollutant in the ambient air, in varying quantities."

The pollutants originally designated as "criteria pollutants" because of their ubiquitous distribution and potential to endanger health were photochemical oxidants (later regulated as ozone), particulate matter (later regulated as total suspended particulates, then as $\mathrm{PM}_{10}$, and $\mathrm{PM}_{2.5}$ ), carbon monoxide, sulfur oxides (regulated as sulfur dioxide), nitrogen oxides (regulated as $\mathrm{NO}_{2}$ ), and non-methane hydrocarbons (later dropped as a criteria pollutant). The EPA (1971) established NAAQS for these pollutants, soon after the Agency was created, using existing scientific documentation, i.e., criteria. As I will discuss below, the EPA later added lead as a criteria pollutant with legal prodding from the National Resources Defense Council.

In 1977, several key amendments were made to the CAA (1977). Concern about slow action of the EPA in preparing criteria documents and reassessing NAAQSs prompted a legislated requirement that the NAAQSs be reevaluated not later than January 1, 1980, and at 5-year intervals thereafter. Reevaluation was not intended to automatically result in changes in the NAAQSs for a pollutant; rather, reevaluation was intended to ensure that the scientific database was reviewed and that the NAAQSs were consistent with current knowledge. To my knowledge, this requirement for mandatory review every 5 years is unique to the setting of the NAAQS in the United States. Indeed, I know of no other statute calling for an updating of the science and reconsideration of the Standard every 5 years.

Peer review of the earliest criteria documents prepared by the EPA was carried out by various committees of the agency's Science Advisory Board as I will discuss later. A 1977 amendment to the CAA institutionalized the peer-review process for the NAAQS (CAA 1977). The amendment requires the EPA Administrator to appoint an independent scientific committee, composed of seven members, including at least one member of the National Academy of Sciences, one physician, and one person representing state air pollution control agencies to advise the Administrator on the science informing the policy judgments made in setting the NAAQS. The EPA has implemented this provision of the CAA by appointing a Committee, which designated itself as the CASAC. The CASAC is directly responsible to the EPA Administrator, although it functions administratively as one of the standing committees of the EPA Science Advisory Board. Traditionally, the requirement for one CASAC member to be a member of the National Academy of Sciences has been broadly interpreted to also include membership in either the National Academy of Engineering or the Institute of Medicine. To complement the expertise of regular members of the CASAC, consultants with specialized expertise usually have been added to the review panels for specific pollutants.

The CAA was amended again in 1990 (CAA 1990). Although major changes were made in the CAA with these amendments, especially with regard to the regulation of hazardous air pollutants, there were no changes in the fundamental approach to dealing with the setting of NAAQS for criteria pollutants. However, there were changes in the CAA that have had major impact on the regulation of emissions of PM and precursors especially from large power plants.

\section{National Ambient Air Quality Standards}

Section 109 of the CAA (1970) directs the Administrator to propose and promulgate "primary" and "secondary" NAAQSs for criteria pollutants identified under Section 108. The primary Standards are to be set to protect public health; secondary Standards are to be set to protect the 
public welfare such as effects on soils, water, crops, visibility, and deterioration of property. In this paper, I focus on the use of scientific knowledge and judgment in the setting of the primary Standards. However, the issues discussed are also broadly applicable to the setting of secondary Standards.

Section 109(b)(1) defines a primary NAAQS as one that "the attainment and maintenance of which in the judgment of the Administrator, based on the criteria and allowing an adequate margin of safety, is requisite to protect the public health." The margin of safety, as interpreted by the EPA, is intended to address uncertainties associated with inconclusive scientific and technical information at the time the Standard is set and to account for hazards that research has not yet identified.

The primary Standards are intended to protect against "adverse effects, not necessarily against all identifiable effects of changes produced by a pollutants." Although Congress did not rigorously define an adverse effect, it did provide general guidance in the legislative history of the debate on the CAA (Library of Congress 1974). Congress was concerned with effects ranging from cancer, metabolic and respiratory disease, and impairment of mental processes to headaches, dizziness, and nausea.

Congress also noted concern for sensitive population groups in setting the NAAQSs. In particular, Congress noted that the Standards should protect "particularly sensitive citizens such as bronchial asthmatics and those with emphysema who in the normal course of daily activity are exposed to the ambient environment." This has been interpreted to exclude individuals who are not performing normal activities, such as individuals who are hospitalized. Further guidance was given noting that the Standard is statutorially sufficient whenever there is "an absence of adverse effect on the health of a statistically related sample of persons in sensitive groups from exposure to the ambient air."

The challenge of interpreting the language of the CAA was noted in an editorial by Donald Kennedy on "Risk versus Risk" published when he served as Editorin-Chief of Science (Kennedy 2005). He wrote-_"In the United States and some other industrial democracies, where people and their governments tend to be risk averse, legislatures, courts, and administrative entities usually create a presumption favoring more safety rather than less. The definitions of risk in law are often vague ("reasonable certainty of no harm" or "adequate margin of safety") and are likely to encourage an unrealistic belief that risks can be minimized or even eliminated altogether." I think Kennedy has captured the conundrum posed by the language of the CAA, a conundrum that has been addressed by Supreme Court Justice Stephen Breyer as I will relate later.
Standard-setting process

The process for developing and issuing NAAQS is quite complex. Key elements of the process, as used until quite recently, include preparation and review of (a) criteria document, (b) staff paper, (c) more recently a risk assessment, and (d) a regulatory decision package leading to the Administrator's policy judgment decisions as to the proposed and final NAAQS which are published in the Federal Register. Traditionally, CASAC focused its attention on reviewing the Criteria Documents and Staff Papers and, more recently, a formal Risk Assessment. As an aside, the process was changed at the end of 2006 (Peacock 2006) with an Integrated Science Assessment and Policy Assessment Document replacing the Criteria Document and Staff Paper. Time will tell if these changes really improve the overall process.

In addition to the documents noted above, the Agency now prepares a Regulatory Impact Analysis which is required under Executive Order 12866 issued by President Clinton (1993) that applies to economically significant rules that have "an annual effect on the economy of $\$ 100$ million or more or adversely effect in a material way the economy, a sector of the economy, productivity, competition, jobs, the environment, public health or safety or site, local, or tribal governments or communities." The Regulatory Impact Analysis is not considered during the NAAQS rulemaking process given the prohibition of consideration of cost in the setting of the NAAQS, as will be discussed later.

The first Criteria Document prepared and released by the EPA addressed lead as a criteria air pollutant. This document was prepared and the review initiated before a Clean Air Scientific Advisory Committee was mandated by the CAA Amendments of 1977. Lead was not one of the original criteria pollutants. In 1975, the Natural Resources Defense Council (NRDC), with legal leadership from Attorney David Schoenbrod, sued EPA to have lead listed as a criteria pollutant. The EPA argued that it was already dealing effectively with reducing lead in air through its program to remove lead from gasoline. The Second Circuit Court disagreed (NRDC v. Train 1976) and on March 1, 1976, ordered EPA to identify lead as a criteria pollutant and begin the process of developing a NAAQS. At the time, EPA's Science Advisory Board (SAB) was in the process of assuming review responsibility for scientific activities across the Agency consolidating review functions brought to EPA from its predecessor organizations such as the National Air Pollution Control Administration (NAPCA). The EPA had just disbanded the National Air Quality Criteria Advisory Committee which had operated under NAPCA as well as other media specific advisory committees in favor of a series of discipline-oriented Committees; e.g., health, engineering and ecology. 
In 1976, I was asked, as a member of the SAB Executive Committee, to chair an ad hoc Committee to review the criteria document on lead. Preparation of this document had already been initiated by EPA in anticipation of the Second Circuit Court decision. It was prepared by a Criteria and Special Studies Office within the Office of Research and Development located at EPA's Health Effects Laboratory in Research Triangle Park, NC. The first draft, released November 18, 1976, was viewed as unacceptable by the Ad Hoc Committee. The Committee was concerned with the poor scientific quality of the document. In addition, as noted by Bachmann (2007), the Committee was concerned that the document recommended a specific numerical Standard, a value of $5 \mu \mathrm{g} / \mathrm{m}^{3}$, which was inconsistent with the intent of the CAA to separate the scientific assessment of the relevant criteria and the setting of the specific NAAQS.

The views of the Ad Hoc Committee members varied. Indeed, some members wanted the Committee to assume responsibility for re-writing the Criteria Document and recommending a specific Standard. As Chair, I emphasized our role was advisory to the Administrator, not to serve as substitutes for EPA staff to prepare the Criteria Document. The EPA proceeded to prepare a second draft which was released on May 27, 1977. The Committee viewed it as improved, but felt it was still not adequate for setting a lead Standard. The Agency proceeded to develop a third draft released on August 22, 1977. The Committee offered modest comments on the third draft which were considered by the Agency as it prepared the final criteria document released on December 14, 1977 (EPA 1977a) which served as a basis for the proposed lead NAAQS (EPA 1977b). As Chair, I conveyed to the Agency the view that the final version - "accurately reflected the available scientific literature and provided an adequate scientific basis for promulgation and issuance of a Standard for airborne lead." The first lead NAAQS was issued in 1978 (EPA 1978).

The experience with the lead criteria document served as a stimulus for EPA to create a separate Environmental Criteria Assessment Office within the Agency's Office of Research and Development. For three decades, this office was headed by Lester Grant. Grant originally came to the EPA from the University of North Carolina-Chapel Hill as an Inter-Government Personnel Act assignee to assist with revision of the criteria document on lead.

As noted by Bachmann (2007), the Office of Air Quality Planning and Standards (OAQPS) prepared an analysis to support the Lead Standard which was reviewed by EPA scientists, policymakers and the public. However, it was not reviewed by the SAB Ad Hoc Committee. That analysis served as a basis for the proposed NAAQS for lead (EPA 1977b) and the final lead NAAQS (EPA 1978). Bachmann (2007) has noted-“"As for all NAAQS decisions, the final choice on the Standard was constrained and informed by the scientific information, but ultimately based on the policy judgment of a politically responsible decision-maker, the EPA Administrator. After consideration of and reaction to public comments, and review and discussion on the final package by $\mathrm{OMB}$, the Administrator promulgated $\mathrm{a} \mathrm{Pb}$ Standard of $1.5 \mu \mathrm{g} / \mathrm{m}^{3}$ quarterly average in TSP." I strongly agree with Bachmann's first sentence assessment of the role of scientific information informing the policy judgments of the EPA Administrator. This will be a recurring theme in the remainder of this paper.

In many ways, the experience EPA gained in setting the lead NAAQS influenced the NAAQS process for subsequent NAAQS decisions. The OAQPS analysis evolved into preparation of formal Staff Papers that would be subjected to review by the CASAC. The first activity of the newly created CASAC, initially chaired by Sheldon Friedlander, was the review of a combined criteria document for particulate matter and Sulfur Oxides. Subsequently, separate addenda were prepared for Sulfur Oxides and particulate matter and separate Standards issued for the two pollutants. Sulfur Dioxide was identified as the indicator for Sulfur Oxides and Total Suspended Particulate (TSP) as the indicator for particulate matter.

Without going into the administrative or legal details, it is important to note that EPA, in carrying out mandated NAAQS actions in the early days, used an "informal rulemaking process" to propose and promulgate Standards (Bachmann 2007). The informal process focused on the end product, the NAAQS. The process was not always well documented as to how decisions were reached on the four elements of each NAAQS; the indicator, averaging time, specific numerical concentration and the statistical form. The DC Circuit Court of Appeals subsequently found that the record of this informal process did not give the Court a sufficient basis to complete its judicial review of the rules that were promulgated. This led to the final rule for the secondary Sulfur Dioxide Standard being revoked in 1973 as recounted by Berry (1984) in his review of NAAQS decision-making. This judicial decision led EPA to develop more rigorous procedures, including documentation, for the setting of each NAAQS (Pedersen 1975). As noted by Bachmann (2007), these procedures addressed the following points: "(1) EPA was to make available to the public the information and technical methodologies it relied upon by the time of proposal; (2) the preambles to proposal and final rules were to provide a detailed explanation of EPA's decision; (3) EPA was required to respond to all "significant" comments on the proposal by the time it issues its final rule; and (4) all of the above documents, analyses, preambles, and responses constituted the record that the court would examine in reviewing the final Standard decision. Objections not raised 
in the record could not be raised in court. The halcyon days of a speedy NAAQS process were over." I agree that the speed of the process was reduced, however, I would add that the transparency of the process was also substantially improved. Congress apparently agreed and these provisions were substantially codified by the CAA Amendments of 1977.

EPA's implementation of the CAA, especially its setting of NAAQS even with improved documentation, has been a matter of continuing controversy and litigation (some persons might argue that controversy and litigation were enhanced by improved documentation in the record). Bachmann (2007) summarizes many of the key legal cases in his review. In this paper, I will only highlight certain of the key legal cases.

The 1997 revisions of the Ozone NAAQS (EPA 1997a) and Particulate Matter NAAQS (EPA 1997b) proved to be very contentious, including the discussions within CASAC. The CASAC PM Panel members had a range of views on the $\mathrm{PM}_{2.5}$ Standard that was being set for the first time supplementing the $\mathrm{PM}_{10}$ Standard. This range of views was clearly articulated in the CASAC Chair's letter (Wolff 1996) to the Administrator by including a Table showing the views of each individual.

The contentious nature of the debate over these revised NAAQS prompted Administrator Browner to involve President Clinton. Bachmann (2007) recounts that Administrator Browner had a 1-h meeting on these Standards with the President- "she reported that the President quickly accepted her decision and spent much of the time discussing how to reduce unnecessary burdens in the implementation process. This resulted in some of us writing the first draft of a letter that was later sent by President Clinton (Clinton 1997) to EPA directing implementation be carried out so as to "maximize common sense, flexibility, and cost effectiveness."' Not surprisingly, President Clinton (New York 1997) had a role in announcing the tighter Standards which included for the first time a separate $\mathrm{PM}_{2.5}$ Standard to supplement the $\mathrm{PM}_{10}$ Standard and a shift from a 1-h averaging time to an 8 -h averaging time Standard for Ozone.

The issuance of a revised PM NAAQS triggered the case of American Trucking Associations v. EPA (ATA 1999). The Court found "the growing empirical evidence demonstrating a relationship between fine particle pollution and adverse health effects amply justifies establishment of new fine particulate Standards." The Court went on to find "ample support" for EPA's decision to regulate coarse particulate pollution, but vacated the $1997 \mathrm{PM}_{10}$ Standards, concluding in part that $\mathrm{PM}_{10}$ is a "poorly matched indicator for coarse particulate pollution" because it includes fine particulates which were separately regulated as $\mathrm{PM}_{2.5}$. Subsequently, EPA removed the vacated $1997 \mathrm{PM}_{10}$ Standard allowing the $1987 \mathrm{PM}_{10}$ Standard to remain in place along with the new $\mathrm{PM}_{2.5}$.
In addition, the three judge panel held, two to one, that EPA's approach to setting the level of the PM and Ozone Standards in 1997 effected "an unconstitutional delegation of legislative authority." The Judicial Panel found that "the factors EPA uses in determining the degree of public health concern associated with different levels of ozone and particulate matter are reasonable." However, it remanded the rule to EPA. The Judicial Panel stated that when the Agency considers these factors for potential non-threshold pollutants "what EPA lacks is any determinate criterion for drawing lines" to determine the level at which the Standards should be set. The Judicial Panel also found that the Administrator, under the CAA, is not permitted to consider the cost of implementing these Standards in setting them.

Not surprisingly, the nature of the Circuit Court opinion resulted in cross appeals being filed on the several issues. The Supreme Court in February 2001 issued a unanimous opinion upholding EPA's position on both the Constitutional and cost issues (Whitman v. American Trucking Associations 2001). On the Constitutional issue, the Supreme Court held that the statutory requirement that the NAAQS be "requisite" to protect public health with an adequate margin of safety sufficiently guided EPA's discretion, affirming EPA's approach of setting Standards that are neither more nor less stringent than necessary.

Supreme Court Justice Breyer, who participated in the Whitman v. American Trucking Associations Case, is well known and highly regarded for his opinions and writings on risk assessment and regulation (Breyer 1982, 1993). Thus, it is not surprising that he took the opportunity in Whitman v. American Trucking Associations (2001) to offer comments on the Standard-setting process and, specifically, the identification of the level of the NAAQS and the associated level of health risk. While concurring that EPA cannot consider the costs of implementing the NAAQS, he went on to note-this interpretation of $\$ 109$ does not require the EPA to eliminate every health risk, however slight, at any economic cost, however great, to the point of "hurtling" industry over "the brink of ruin," or even forcing "deindustrialization." (Id. At 494; Breyer, J., concurring in part and concurring in judgment; citations omitted). Rather, as Justice Breyer explained:

"The statute, by its express terms, does not compel the elimination of all risk; and it grants the Administrator sufficient flexibility to avoid setting ambient air quality Standards ruinous to industry.

Section 109(b)(1) directs the Administrator to set Standards that are "requisite to protect the public health" with "an adequate margin of safety." But these words do not describe a world that is free of all riskan impossible and undesirable objective (citation omitted). Nor are the words "requisite" and "public 
health" to be understood independent of context. We consider football equipment "safe" even if its use entails a level of risk that would make drinking water "unsafe" for consumption. And what counts as "requisite" to protecting the public health will similarly vary with background circumstances, such as the public's ordinary tolerance of the particular health risk in the particular context at issue. The Administrator can consider such background circumstances when "deciding what risks are acceptable in the world in which we live." (citation omitted).

The statute also permits the Administrator to take account of comparative health risks. That is to say, she may consider whether a proposed rule promotes safety overall. A rule likely to cause more harm to health than it prevents is not a rule that is "requisite to protect the public health." For example, as the Court of Appeals held and the parties do not contest, the Administrator has the authority to determine to what extent possible health risks stemming from reductions in tropospheric ozone (which, it is claimed, helps prevent cataracts and skin cancer) should be taken into account in setting the ambient air quality Standard for ozone. (citation omitted).

The statute ultimately specifies that the Standard set must be "requisite to protect the public health" "in the judgment of the Administrator," §109(b)(1), 84 Stat. 1680 (emphasis added), a phrase that grants the Administrator considerable discretionary Standardsetting authority.

The statute's words, then, authorize the Administrator to consider the severity of a pollutant's potential adverse health effects, the number of those likely to be affected, the distribution of the adverse effects, and the uncertainties surrounding each estimate (citation omitted). They permit the Administrator to take account of comparative health consequences. They allow her to take account of context when determining the acceptability of small risks to health. And they give her considerable discretion when she does so.

The discretion would seem sufficient to avoid the extreme results that some of the industry parties fear. After all, the EPA, in setting Standards that "protect the public health" with "an adequate margin of safety," retains discretionary authority to avoid regulating risks that it reasonably concludes are trivial in context. Nor need regulation lead to deindustrialization. Pre-industrial society was not a very healthy society; hence a Standard demanding the return of the Stone Age would not prove "requisite to protect the public health."

Although I rely more heavily than does the Court upon legislative history and alternative sources of statutory flexibility. I reach the same ultimate conclusion, Section 109 does not delegate to the EPA authority to base the national ambient air quality Standards, in whole or in part, upon the economic costs of compliance."

The case of Whitman v. American Trucking Associations (2001) is widely cited for the conclusion that EPA cannot consider the economic costs of compliance in the setting of NAAQS. Unfortunately, in my opinion, insufficient attention is given to the thoughtful guidance of Justice Breyer on exercising policy judgment in deciding on an acceptable level of health risk, a judgment that in turn determines the level and statistical form of each NAAQS. It is interesting that Justice Breyer's opinion appeared in Administrator Johnson's notice of the Ozone NAAQS (EPA 2008), but did not appear in Administrator Jackson's "reconsideration" proposal for ozone (EPA 2010a) which will be discussed later.

\section{Paradigm shift}

At this juncture, it is appropriate to note that it is my view that a paradigm shift has taken place in the use of scientific knowledge and policy judgments in the selection of the level and form of each NAAQS over the past four decades. In my opinion, the paradigm shift has been driven in part by the nature of the growing body of scientific evidence of pollution effects. In the 1970 s, most scientists and regulators viewed the criteria pollutants as having a threshold in the concentration-response relationship for non-cancer endpoints, the major concern for the criteria pollutants. This was different than the prevailing view for cancer causing agents which were assumed to have linear, non-threshold, concentration-response relationships.

In the early 1970s, the available data on each criteria pollutant were quite modest, with attention in the review process focusing on only a few epidemiological studies. For those few studies, attention often focused on whether a relative risk on the order of 2.0 was observed and whether it was statistically significant or not. For a given criteria pollutant there were few, if any, controlled human exposure studies. The data from laboratory animal studies had frequently been acquired in short-term studies with exposure concentrations much higher than ambient concentrations. This raised questions about extrapolation from laboratory animals to humans and high to low exposure concentrations. The general approach taken to evaluating the published studies was to identify the lowest levels where effects were statistically significant and assume this was the inflection point in the concentration-response relationship. It could then be readily argued that setting the Standard at a lower concentration than that at which 
effects were observed satisfied the requirement for "an adequate margin of safety."

In contrast, the most recent reviews of the criteria pollutants have involved thousands of papers with observations ranging from the human population level to studies of intact laboratory animals to studies of effects of air pollutants on cells and molecules. Despite the huge number of published studies, the focus has ultimately centered in the Staff Paper on the results of a few studies where attention turns to the relevance of the results for informing policy judgments on the level and statistical form of the Standard. For the epidemiological studies, the debate often focuses on whether relative risks of less than 1.1 for excess morbidity and mortality are significant. Of course, the specific relative risk number is dependent on the denominator being used. For controlled exposure clinical studies, attention has focused on the lowest levels with statistically significant changes and whether the changes are adverse.

A news report (Taube 1995) in Science, that I view as a classic report, highlighted the issues involved in the search for subtle links between diet, lifestyle, or environmental factors and disease, especially using retrospective observational studies. I especially liked the quote at the end attributed to UCLA Professor Greenland in offering advice to his "most sensible, level-headed, estimatable colleagues." Remember, he says — "there is nothing sinful about going out and getting evidence, like asking people how much do you drink and checking breast cancer records. There's nothing sinful about seeing if that evidence correlates. There's nothing sinful about checking for confounding variables. The sin comes in believing a casual hypothesis is true because your study came up with a positive result, or believing the opposite because your study was negative."

It is interesting to note that CASAC discussions of criteria pollutant effects have frequently focused initially on the level of the Standard, devoid of any consideration of the statistical form of the level. This approach was in keeping with traditional practice in the setting of Standards such as Threshold Limit Values for occupational exposures to chemicals (McClellan 1999, 2010c). That approach has traditionally involved a review of the available human data on a toxic chemical to determine a no-observed effect level, or the lowest observed effect level, and then use of a safety factor to arrive at an acceptable exposure level set at a lower level. In the absence of adequate human data, laboratory animal data are used and an additional safety factor applied to account for the potential that the animal observations might not adequately predict human effects. This approach was routinely used for a wide range of health responses that were assumed to have an exposure-response relationship that exhibited either a true or practical threshold, an excess of effects above some level and an absence of effects below that level. A review of the earliest Criteria Documents and, indeed, also the Staff Papers, documents that a similar line of reasoning was used in the setting of the NAAQS - identify levels where an increase in effects is observed and then set the Standard at a lower level.

The implementation of Standards set with this approach soon revealed that if the Standard was to be rigorously enforced, i.e., no exceedances of the specific level of the Standard, the practical effect would be to cause average levels of the pollutant to be reduced to levels far below the Standard so as to avoid the occasional high concentration exceeding the Standard. Fortunately, common sense prevailed and the EPA, over time, moved to the practice of routinely linking attainment of the specific level of the Standard to a statistical form such as the 98th percentile 24-h concentration averaged over 3 years, or the fourth highest 8-h average concentration during a 3-year period. In my experience, most of the attention of the CASAC in the NAAQS-setting process has focused on the level of the Standard with limited discussion of the statistical form of the Standard. In doing so, there has been a failure to recognize that the stringency of the Standard and the degree of health protection provided depends on both the level and statistical form of the Standard for a particular indicator and averaging time. In fact, there have been occasions when CASAC has deliberated at length on the level of a prospective Standard and, then in a casual manner, turned its attention to what would be the appropriate statistical form for that level. That this is the case is not surprising since few scientific papers discuss the implications of the reported results in terms of the frequency with which a given health effect may be observed.

The challenges of selecting appropriate averaging times and statistical forms for the NAAQS are substantial. The original epidemiological and toxicological studies that provide the scientific information that should inform the setting of the NAAQS do not always report results with an averaging time that is the same as used for the Standard. Hence, the need to make extrapolations from results reported based on one metric, such as average daily exposure, to second metric, such as an 8 -h or shorter averaging time. The setting of Standards at extreme values, the 98th percentile for $\mathrm{NO}_{2}$ (EPA 2010b) and the 99th percentile form as done with the 1-h averaging time Standard for $\mathrm{SO}_{2}$ (EPA 2010c), results in extremely stringent Standards that at best are only very loosely related to the underlying data.

In my view, decisions on the selection of specific levels and averaging times for the NAAQS are policy judgments properly reserved to the Administrator informed by the available scientific knowledge. In the 1990s, concurrent with the increasingly widespread use of formal risk analysis 
procedures across society (McClellan 1999, 2010c), EPA moved to quantify the health benefits associated with setting the NAAQS at various levels, with an associated statistical form. I must admit to being an early advocate of formal quantification of health benefits of various levels and forms of the prospective Standards. I viewed the approach then and I still do today, as a way to synthesize the science so it could provide useful guidance to the Administrator for making policy decisions. I did not envision that some advocates of quantitative risk analysis would actually view the results of the analyses as being highly accurate projections of potential health benefits expressed to two or more significant figures, sometimes without any indication of uncertainty.

The quantification of health effects potentially associated with various levels and forms of the Standards requires several kinds of input. First and foremost, it requires some knowledge of the nature of the concentration-response relationships for various temporal metrics for the pollutant in question. Typically, the response term is expressed as excess risk per unit of increased concentration over some range of ambient concentrations. The question then becomes one of whether the relationship is linear and whether there is a threshold level below which the coefficient for excess risk does or does not hold. The issue of whether there are or are not thresholds for non-cancer health endpoints is very contentious and a subject of on-going debate (White et al. 2009; Rhomberg et al. 2011). A related issue becomes the selection of suitable reference baseline statistics for the particular health effects. An additional question becomes the appropriate population to be evaluated-a single city, multiple cities or the population of the United States. It is obvious that there are substantial uncertainties associated with each component of the analyses.

With the use of linear, no-threshold, concentrationresponse models, the EPA has on some occasions calculated estimated excess morbidity and mortality effects attributable to the specific pollutant down to background concentrations. The Health Risk Assessment (EPA 2007b) and the Regulatory Impact Analysis (EPA 2007d) for the 2008 Ozone NAAQS serve as examples. Further, dependent on the assumptions made with regard to how ambient concentrations of the pollutant would change in response to various levels and forms of the Standard, estimated health effects avoided (i.e. health benefit) may be calculated. A key consideration as to whether these benefits can be realized relates to whether the roll-back in air concentrations that is assumed in the analysis as a result of implementation of the new Standard can actually be realized. In part, the validity of the analyses relate to how realistic the assumptions have been with regard to background levels. A discussion of this issue for ozone can be found in McClellan et al. (2009). Indeed, as the levels of the Standards are ratcheted down toward background levels, there is increasing uncertainty as to whether there are any health effects attributable to single pollutants and even greater uncertainty as to the magnitude of the health benefits associated with any new lower Standard. The use of single pollutant models for estimating benefits also raises the issue of double-counting of benefits as the benefits of the individual pollutants are aggregated.

Hence, the paradigm shift. It is apparent that in setting the earliest NAAQS some individuals, including CASAC members, envisioned that the Standards were being set at levels protective of public health with an adequate margin of safety based on threshold concentration-response models. In short, if there were health effects at the level and form of the selected NAAQS, they were viewed as de minimis. In contrast, more recent NAAQS have been set at levels which the CASAC and EPA characterize as having residual health effects even if the Standard were to be attained. The central question remains - how low is low enough? I view the answer as a policy judgment informed by science that can only be made by the EPA Administrator.

Recent action on revision of the particulate matter and ozone NAAQS

It is instructive to now turn our attention to the most recent actions of EPA with regard to the revision of the PM NAAQS in 2006 (EPA 2006b), the revision of the Ozone NAAQS in 2008 (EPA 2008) and the "reconsideration" proposal (EPA 2010a) for a further revision of the Ozone NAAQS in 2011

In the initial discussion, I will focus on the EPA's 2006 revision of the $\mathrm{PM}_{2.5}$ Standard. The science that informed the setting of that Standard was summarized in a Criteria Document (EPA 2004). This, in turn, provided the basis for the Staff Paper (EPA 2005). The central issue was the level and associated form of the two different averaging time Standards, a 24-h averaging time and an annual Standard. The first Standards using $\mathrm{PM}_{2.5}$ as an indicator were set in 1997 (EPA 1997a). The 24-h averaging time Standard was set at $65 \mu \mathrm{g} / \mathrm{m}^{3}$. The 24-h $\mathrm{PM}_{2.5}$ Standard of $65 \mu \mathrm{g} / \mathrm{m}^{3}$ was attained when the 3-year average of the 98th percentile of the concentrations at each population-oriented monitor was not exceeded. The Annual Standard was set at an annual arithmetic mean of $15 \mu \mathrm{g} / \mathrm{m}^{3}$. The annual Standard was attained when the 3-year average of the weighted $\mathrm{PM}_{2.5}$ concentration from single or multiple community-oriented monitors did not exceed $15 \mu \mathrm{g} / \mathrm{m}^{3}$. Recall that the 1997 $\mathrm{PM}_{2.5}$ Standard was originally intended to supplement and, in part, replace the $\mathrm{PM}_{10}$ (annual arithmetic mean of $50 \mu \mathrm{g} / \mathrm{m}^{3}$ and $24 \mathrm{~h}$ average of $150 \mu \mathrm{g} / \mathrm{m}^{3}$ ) Standard set in 1987. That $\mathrm{PM}_{10}$ Standard had replaced the earlier Total Suspended Particulate Standard promulgated in 1971. 
I participated as a member of the CASAC Panel that provided advice on the setting of the $\mathrm{PM}_{2.5}$ Standard in 1997. There was much discussion about the uncertainty associated with the shift from a $\mathrm{PM}_{10}$ to a $\mathrm{PM}_{2.5}$ Standard, especially the uncertainty in a shift from dependence on only the $\mathrm{PM}_{10}$ indicator to $\mathrm{PM}_{2.5}$ indicator. There was strong scientific support for introducing the $\mathrm{PM}_{2.5}$ indicator, although at the time, there was limited epidemiological data from studies in which $\mathrm{PM}_{2.5}$ had actually been measured. There was no clear scientific evidence on the presence or absence of a threshold in the concentration-response relationship for either acute or chronic responses. The big issues related to the levels and associated form-"how low was low enough?" The prevailing tone in hallway conversations focused on two points. First, it was argued that it was important to introduce a $\mathrm{PM}_{2.5}$ indicator which, in turn, would mandate the monitoring of $\mathrm{PM}_{2.5}$. The availability of the $\mathrm{PM}_{2.5}$ monitoring data would then allow the conduct of epidemiological studies to directly evaluate a potential concentration-response association for this indicator. Second, it was argued that in the absence of convincing data on $\mathrm{PM}_{2.5}$ the final action contemplated by the Agency should not represent a drastic increase in the stringency of the PM Standard. In my opinion the new $\mathrm{PM}_{2.5}$ annual Standard set at $15 \mu \mathrm{g} / \mathrm{m}^{3}$ did increase the stringency of the PM Standard and represented a policy judgment call on the part of the Administrator that was very precautionary. In contrast, in my opinion, the setting of $\mathrm{PM}_{2.5}$ 24-h averaging time Standard at $65 \mu \mathrm{g} / \mathrm{m}^{3}$ was much less precautionary. The level and form of the new Standards was as follows:

(1) The annual $\mathrm{PM}_{2.5}$ Standard is met when the 3-year average of the annual arithmetic mean $\mathrm{PM}_{2.5}$ concentrations, from single or multiple community-oriented monitors, is less than or equal to $15 \mu \mathrm{g} / \mathrm{m}^{3}$, with fractional parts of 0.05 or greater rounded up.

(2) The 24-h $\mathrm{PM}_{2.5}$ Standard is met when the 3-year average of the 98th percentile of 24-h $\mathrm{PM}_{2.5}$ concentrations at each population-oriented monitor within an area is less than or equal to $65 \mu \mathrm{g} / \mathrm{m}^{3}$, with fractional parts of 0.5 or greater rounded up.

(3) The form of the previous 24-h $\mathrm{PM}_{10}$ Standard is revised to be based on the 3-year average of the 99th percentile of 24-h $\mathrm{PM}_{10}$ concentrations at each monitor within an area.

Review of the PM Standard that would lead to revision of the 1997 PM Standard moved forward in the early 2000s. In 2004, as the new Criteria Document for PM was reviewed, it was decided that the CASAC would abandon CASAC's practice of issuing "closure letters." "Closure Letters" had traditionally been sent by the CASAC Chair to the EPA Administrator at key junctures, such as completion of revision of a Criteria Document or Staff Paper, signifying the work product was scientifically acceptable for regulatory decision-making. Some individuals had viewed the "closure letters" as a way by which CASAC impeded progress in the setting of NAAQS in a timely manner. I viewed the "closure letters" as an effective approach to ensuring that EPA was preparing documents that included the latest scientific information and analyses, even if it required the Agency to develop Revisions or Addendums.

After reviewing and commenting on the Criteria Document (EPA 2004) and Staff Paper (EPA 2005), CASAC recommended that the 24-h $\mathrm{PM}_{2.5}$ Standard be set in the range of $25-35 \mu \mathrm{g} / \mathrm{m}^{3}$ and the annual $\mathrm{PM}_{2.5}$ Standard be set in the range of 13-14 $\mu \mathrm{g} / \mathrm{m}^{3}$ (Henderson 2005, 2006a; Table 1).

There was strong pressure within the CASAC PM Panel to provide consensus advice to the Administrator. In the end, two consultant members of the PM Panel who had both served as Chair of CASAC (myself and another) did not deem it appropriate to join with other members of the Panel in endorsing the specific levels others wished to recommend to the Administrator. I held strongly to the view that the difference between leaving the Standard at $15 \mu \mathrm{g} /$ $\mathrm{m}^{3}$ and reducing it to $14 \mu \mathrm{g} / \mathrm{m}^{3}$ was not a scientific decision, but rather a matter of policy judgment that should be left to the discretion of the Administrator. In my opinion, Administrator Johnson, as the politically responsible decision-maker (using the words of John Bachmann 2007 in describing the 1974 Lead NAAQS decision) was not bound by the recommendations of CASAC as they were an advisory committee. In my opinion, the Administrator alone had the authority to make policy judgment calls in retaining or revising the annual $\mathrm{PM}_{2.5}$ Standard, then at $15 \mu \mathrm{g} / \mathrm{m}^{3}$ and the 24-h $\mathrm{PM}_{2.5}$ Standard, then at $65 \mu \mathrm{g} / \mathrm{m}^{3}$ (EPA 1997a). The Administrator issued a final rule with the annual $\mathrm{PM}_{2.5}$ Standard retained at $15 \mu \mathrm{g} / \mathrm{m}^{3}$ and the 24-h Standard reduced to $35 \mu \mathrm{g} / \mathrm{m}^{3}$ (EPA 2006b).

Table 1 National ambient air quality standards for $\mathrm{PM}_{2.5}$ and ozone, the old standard, CASAC recommendations and administrator's final rule

\begin{tabular}{lccc}
\hline Indicator (unit) & Old standard & CASAC & New standard \\
\hline $\mathrm{PM}_{2.5}-24 \mathrm{~h}\left(\mu \mathrm{g} / \mathrm{m}^{3}\right)$ & $65^{\mathrm{a}}$ & $30-35^{\mathrm{b}}$ & $35^{\mathrm{c}}$ \\
Annual $\left(\mu \mathrm{g} / \mathrm{m}^{3}\right)$ & $15^{\mathrm{a}}$ & $13-14^{\mathrm{b}}$ & $15^{\mathrm{c}}$ \\
Ozone-8 $\mathrm{h}(\mathrm{ppb})$ & $84^{\mathrm{d}}$ & $60-70^{\mathrm{e}}$ & $75^{\mathrm{f}}$ \\
\hline
\end{tabular}

\footnotetext{
${ }^{\mathrm{a}}$ EPA $1997 \mathrm{a}, \mathrm{b}$

${ }^{\mathrm{b}}$ Henderson 2006a, b; Henderson et al. 2006c

${ }^{\mathrm{c}}$ EPA 2006b

${ }^{\mathrm{d}}$ EPA $1997 \mathrm{a}, \mathrm{b}$, set at $0.08 \mathrm{ppm}$ which by rounding convention equals $84 \mathrm{ppb}$

${ }^{\mathrm{e}}$ Henderson 2007, 2008

${ }^{\mathrm{f}}$ EPA 2008
} 
After the final PM rule was issued in 2006 (EPA 2006b), the seven formal members of CASAC (Henderson et al. 2006c) sent a letter to the Administrator expressing concern that the EPA Administrator had not decreased the $\mathrm{PM}_{2.5}$ Annual Standard from $15 \mu \mathrm{g} / \mathrm{m}^{3}$ to $13-14 \mu \mathrm{g} / \mathrm{m}^{3}$ in combination with the setting of the 24-h Standard at $35 \mu \mathrm{g} / \mathrm{m}^{3}$, the upper end of the ranges they had recommended. In my view, the CASAC recommendation that the Administrator had to reduce the annual Standard by at least $1 \mu \mathrm{g} / \mathrm{m}^{3}$ indicated that the CASAC failed to appreciate that the setting of any NAAQS involves policy judgments, reserved by the CAA to the EPA Administrator, informed by the science. Presumably, the CASAC would have found it acceptable if the Administrator had reduced the Annual $\mathrm{PM}_{2.5}$ Standard from 15 to $14 \mu \mathrm{g} / \mathrm{m}^{3}$, or even to $13 \mu \mathrm{g} / \mathrm{m}^{3}$.

Perhaps it would be useful for me to elaborate on why I think it is not appropriate for CASAC to recommend a bright line upper bound on the NAAQS, even assuming no change in the statistical form of the Standard. The Committee, when commenting on the science undergirding the Standard, had noted that it had not identified a threshold in the ambient exposure concentration-response relationship for $\mathrm{PM}_{2.5}$. Consistent with this assessment of the science, the EPA in its Risk Assessment had used a linear exposure concentration-response model to estimate risk that would be avoided and risks that would remain if the Standards were set at various specific levels and with an assumed statistical form. There were estimated risks associated with retaining the Standard at $15 \mu \mathrm{g} / \mathrm{m}^{3}$ and reducing it to 14 or $13 \mu \mathrm{g} / \mathrm{m}^{3}$. By endorsing a level of $14 \mu \mathrm{g} / \mathrm{m}^{3}$ for the annual Standard, the CASAC was indicating its support for setting the Standard at a particular level of estimated risk. In my opinion, a decision on acceptable risk (i.e., the residual risk level when the Standard is attained) is a policy decision left to the discretion of the EPA Administrator under the authority of the CAA. The Committee's blended scientific and policy judgment advice would have been clearer if they had stated their specific advice by indicating both the specific numerical level and the associated morbidity and mortality. Of course, the estimates of morbidity and mortality should have had an indication of the associated uncertainties.

Let us now turn to revision of the Ozone NAAQS. Final action on revision of the Ozone Standard set in 1997 (EPA 1997b) followed almost 2 years after the decision on the $\mathrm{PM}_{2.5}$ Standard. The ozone review included a Criteria Document (EPA 2006c) which summarized publications through 2005. This document served as the basis for a subsequent staff paper (EPA 2007a) and risk assessment (EPA 2007b). Again, CASAC (Henderson 2006b, 2007) offered very prescriptive advice on the level of the Standard indicating that the level of the revised 8-h averaging time Standard should be lowered to no greater than $0.070 \mathrm{ppm}$ down from the 1997 Standard of $0.08 \mathrm{ppm}$ which by rounding convention was effectively $0.084 \mathrm{ppm}$. The 1997 Standard is met when the 4th highest 8 -h average value over a 3-year period does not exceed $0.084 \mathrm{ppm}$ (Table 1).

The CASAC letter on the Ozone Staff Paper (Henderson 2007) commented on policy relevant background (PRB) noting "the Final Ozone Staff Paper does not provide a sufficient base of evidence from the peer-reviewed literature to suggest that the current approach to determining a PRB is the best method to make this estimation." The letter concludes with the statement- "Thus, PRB is irrelevant to the discussion of where along the concentration-response function a NAAQS with an averaging time that provides enhanced public health protection should be." The CASAC apparently failed to appreciate that identification of scientifically valid levels for PRB for different sections of the country can have a profound influence on realizable public health benefits (see discussion in McClellan et al. 2009) and the calculated benefit and residual risks for various levels and forms of the Standards.

As the Agency's activities on revision of the Ozone NAAQS were proceeding, I participated in June 2007 with a small group of scientists at a meeting held in Rochester, NY to discuss critical considerations in evaluating scientific evidence of health effects of ambient ozone. The discussions at the Rochester Conference focused on the scientific interpretation of the data available on the health effects of exposure to ambient concentrations of ozone, controlled ozone exposure studies with human volunteers, long-term epidemiological studies, time-series epidemiological studies, human panel studies, and toxicological investigations. The deliberations also dealt with the issue of background levels of ozone of non-anthropogenic origin and issues involved with conducting formal risk assessment of the health impacts of current and prospective levels of ambient ozone. The participants, while offering comments on the science informing the revision of the Ozone NAAQS, did not feel it appropriate to offer policy judgments on the level and form of the Ozone NAAQS then under consideration. A report based on the Rochester Conference has been published (McClellan et al. 2009). The deliberations at the Rochester Conference were summarized and included with my comments (McClellan 2007) submitted to the EPA Ozone Docket on the proposed Ozone Standard (EPA 2007c).

Administrator Johnson, in March 2008 (EPA 2008), issued a final revised Standard for Ozone with the primary 8-h average Standard set at $75 \mathrm{ppb}$ retaining the statistical form the same as the 1997 primary Standard - the Standard is attained when the fourth highest 8 -h average value over a 3 -year period does not exceed $75 \mathrm{ppb}$. The CASAC was displeased with the policy judgment of Administrator Johnson to set the Standard at $75 \mathrm{ppb}$ rather than heeding 
their recommendation to set the Standard in the range of 0.060-0.070 ppm (Henderson 2008). As an aside, Administrator Johnson also decided to set the secondary Standard for Ozone equal to the primary Standard. In doing so, he did not heed CASAC's advice to set a secondary Standard with a different cumulative form. The CASAC had recommended a sigmoidally weighted W126 index, accumulated over 12 "daylight" hours and over at least the three maximum ozone months of the summer growing season (Henderson 2008).

Some CASAC members have argued that by giving the EPA Administrator a range (0.060-0.070 ppm), the CASAC had not taken away the Administrator's discretion in making policy judgments on the level and form of the NAAQS. To the contrary, I argue that the upper value in the range is in effect a bright line that CASAC has indicated the Administrator should not go above based on the science. In short, under the new paradigm, CASAC has defined for the Administrator the upper level of excess risk that CASAC deems acceptable, even though they have not clearly identified the specific health risk level associated with the 0.070 ppm level.

I firmly believe that Administrator Johnson's decisions on both the primary and secondary ozone Standards were consistent with the legislative authority accorded the Administrator under the CAA. Much was made of the fact that in the setting of the Ozone Standards, discussions took place between White House staff and, perhaps then President Bush, as the Standard was finalized. This is hardly surprising. Recall Bachmann (2007) recounted the discussions between President Clinton and Administrator Browner in 1997 and the draft memo to EPA Administrator Browner prepared by EPA staff for ultimate issuance over the signature of President Clinton (Clinton 1997).

As soon as President Obama was sworn in on January 20, 2009, the then-White House Chief of Staff, Rahm Emanuel, issued a memorandum (Emanuel 2009) stating - "It is important that President Obama's appointees and designees have the opportunity to review and approve any new or pending regulations." The Emanuel memorandum then proceeded to outline explicit conditions for what qualified as new or pending regulations-for example, "all proposed or final regulations that have not been published in the Federal Register" and "consider extending for 60 days the effective date of regulations that have been published in the Federal Register but not yet taken effect." The revised NAAQS for ambient ozone, published in the Federal Register, March 12, 2008 (EPA 2008), could hardly be viewed as new or pending in January 2009. Indeed, in the fall of 2008, the EPA had already initiated action on the next review of the Ozone NAAQS (Martin 2008). In initiating the new review, it was noted that CASAC advice on the previous review of the Standard represented "a mixture of scientific and policy considerations." Nonetheless, EPA Administrator Lisa Jackson in late 2009, decided to proceed with "reconsideration" of the final Ozone NAAQS rule issued in March 2008 (EPA 2008). The decision to proceed with a "reconsideration" proposal was formally announced in the Federal Register in January 2010 (EPA 2010a). The "reconsideration" proposal noted-"With respect to CASAC's recommended range of standard levels, EPA observed that the basis for CASAC's recommendation appears to be a mixture of scientific and policy consideration."

Administrator Jackson has stated that the "reconsideration" rule will be based on the same record used to propose the 2008 Standard, essentially the scientific information available through late 2005 and included in the 2006 Criteria Document (EPA 2006a). Recall the earlier discussion of EPA moving to a formal rulemaking process at the insistence of the Court. The approach of using the "old scientific record" was apparently taken with a view that it offered a "fast track" to a revision of the Ozone Standard without creating a new record. The "reconsideration" proposal (EPA 2010a) states that consideration will be given to setting the primary Standard set in the range of 60 to $70 \mathrm{ppb}$. The announced date for release of the final "reconsideration" Standard has continually shifted from August 2010 to October 2010 to December 2010 to July 2011. In accord with the review plan laid out in October 2008, the EPA staff proceeded with preparation of the Integrated Science Assessment reviewing the new scientific information to be considered in the next 5-year review triggered by promulgation of the March 2008 Ozone NAAQS. Ironically, the Integrated Science Assessment, the document replacing the old criteria document, for ozone, was released on March 2, 2011 (EPA 2011a), all while EPA's reconsideration of the old record remains pending.

I offered comments (McClellan 2010a) on the appropriateness of the Administrator proceeding with a "reconsideration" Standard for ozone and offered comments (McClellan 2010b) to the EPA Ozone Docket on the specifics of the proposal. In my view, the proposal for the Administrator to reconsider a rulemaking, the setting of a NAAQS, formally completed 9 months earlier by the previous Administrator in another Administration is without precedent. It has the potential to serve as a bad precedent with every change in Presidential Administration triggering a review of actions completed by the previous Administration with a view to potentially reconsidering the rules. In short, the new Administrator is saying "if I had been in office before I was appointed, I would have made a different policy judgment call." Administrator Jackson's use of the CASAC position in 2008 to justify the "reconsideration" action, in my opinion, moves CASAC out of its scientific advisory role into a strategic, policy-driving 
Standard-setting role. This is troubling since Administrator Johnson, in issuing the 2008 Standard, had noted (perhaps with trepidation) that the CASAC recommendation "appears to be a mixture of scientific and policy considerations," a view informed by EPA staff analysis (Martin 2008). I agree with the assessment that CASAC, in recommending specific levels, is on a path of mixing scientific interpretations with policy judgments.

Administrator Jackson, in early 2011 (EPA 2011b), called on the CASAC to offer further clarification of the views it expressed earlier. The specific advice being solicited by the Administrator from CASAC is detailed in a memorandum from Lydia Wegman, Office of Air Quality Planning and Standards to CASAC (Wegman 2011). Many of the questions appear to be directed at attempting to distinguish between CASAC's interpretation of the old science and the policy judgments that resulted in CASAC's 60-70 ppb recommended range for the Standard. It proved challenging for CASAC to address these questions based only on the "old record" of pre-2006 science while ignoring the new scientific information on ozone (Samet 2011).

The substantial new scientific information on ozone that has been published in the 5 years since the Criteria Document (EPA 2006c) was prepared is documented in the recently released Integrated Science Assessment (EPA 2011b). The current drama over the "reconsideration" ozone rule has the potential to damage the credibility of CASAC by drawing it more tightly into the "regulatory web of policy judgments" that are the exclusive dominion of the Administrator under the authority of the CAA. My advice (McClellan 2011) to the Administrator and CASAC was to withdraw the "reconsideration" proposal and ask CASAC to expeditiously proceed with review of the new science now available in the Integrated Science Assessment (EPA 2011a).

\section{Call for sound science}

Over the last several decades, there have been increasingly loud calls from multiple quarters for using "sound science" to make regulatory decisions such as the setting of NAAQS. The call has come from both Non-Government Organizations (NGOs) representing multiple sectors, from Industry and from the scientific community. In my opinion, all of these groups and the individuals within them have difficulty separating the science from their policy-driven preferred outcomes. As a scientist and as a citizen, I strongly support the use of all the available scientific information to inform public policy decisions. In general, I think the efforts of individuals and organizations to critically review and synthesize relevant scientific information for the various Agency rulemaking activities has had a positive impact. This includes the situations in which original scientific data files were made available (actions that I applaud) and re-analyses conducted. Indeed, I think more such analyses should be conducted, especially when the original data were acquired with public funding. By the same token, I would urge industry groups to make available to other investigators data acquired under industry sponsorship.

What I decry, however, is the desire by some to label certain reviews or analyses as either "acceptable" or "dead on arrival" based on the source of funding without regard to scientific quality of the review or analyses. Over my career, I have encountered exceptionally high-quality reviews and analyses performed by scientists in academic, industrial, and environmental organizations with sponsorship from government, NGOs, and industry. I have also noted some reviews and analyses from these same quarters that I thought were of inferior scientific quality. In my opinion, scientific quality and rigor is not defined by the source of funding for the work.

I have great concern that the advocates of "sound science," be it NGO, academics or industry, may have unrealistic expectations as to what "sound science" can deliver. Sound science does not in and of itself make for sound decisions. As I have noted in this paper, science alone cannot identify an acceptable level of health risk, since such levels inherently represent a policy judgment call. Sound science can only inform what are ultimately policy judgments or political decisions. This is especially the case for the setting of NAAQS, in the absence of a clearly defined threshold, which involve decisions as to acceptable health risks which are linked to the level (and form) of the Standard.

\section{Setting NAAQS at acceptable levels of risk}

Let us now return to the critical issue of "how low is low enough?" for setting a specific NAAQS. It is apparent that the body of science on any given criteria pollutant today is such that it is difficult to argue that the current Standards, if attained, would result in a world that is free of any risk of adverse effects from air pollution on the populations of the United States. As Justice Breyer wrote, we live in a world that is not free of all risk. I draw guidance from Justice Breyer's statement on his interpretation of the words of the CAA - "They permit the Administrator to take account of comparative health consequences. They allow her to take account of context when determining the acceptability of small risks to health. And they give her considerable discretion when she does so." The "her" in Justice Breyer's opinion is a reference to past EPA Administrator Christine Whitman.

However, in my opinion, the discretion that Justice Breyer assigns to the EPA Administrator does not extend to 
the CASAC, either as individuals or acting collectively. Each of the individuals serving on CASAC may be an extraordinarily competent scientist or engineer or have other specialized knowledge of air quality and its health and environmental effects. Because of this special expertise, these individuals have a special role in interpreting the scientific knowledge that the Administrator will use in making policy judgments on the level and form of the Standard recognizing that the level and form, in turn, determine the level of acceptable risk that it is estimated Society will bear for that specific pollutant.

As broadly knowledgeable health and environmental scientists, CASAC members are in a unique position to offer advice to the Administrator that will provide the "comparative health consequences" context that Justice Breyer has called for in his opinion. For example, it would be refreshing if CASAC members were to more broadly draw on their experience as health specialists. In doing so, when debate begins on the public health significance of an excess risk of 0.1 for some health endpoint per $10 \mathrm{ppb}$ increase in ozone at 60,70 , or 80 ppb averaged over $8 \mathrm{~h}$, they could offer comments on the multiple factors that influence the health risks for that endpoint. This discussion, in my opinion, should even be extended to recognize that complex factors such as the socio-economic status of individuals have a profound influence on health (Table 2; Steenland et al. 2004). I will readily admit that differences in air quality associated with socio-economic status may have a role in the differences reported by Steenland et al. (2004) and other investigators. However, that admission does not serve as a basis for not providing scientific context to decisions on "how low is low enough" in setting NAAQS.

I suspect that this was the kind of input Administrator Bill Ruckelshaus was seeking when he noted in 1983 that a decision on the PM Standard "could not be made solely on

Table 2 The impact of socio-economic status on mortality (Steenland et al. 2004)

\begin{tabular}{lll}
\hline Mortality & Men & Women \\
\hline All causes & $2.02(1.95-209)^{\mathrm{a}}$ & $1.29(1.25-1.32)$ \\
Heart disease & $1.88(1.83-1.93)$ & $1.84(1.76-1.93)$ \\
Stroke & $2.25(2.14-2.37)$ & $1.53(1.44-1.62)$ \\
Diabetes & $2.19(2.07-2.32)$ & $1.85(1.72-2.00)$ \\
COPD & $3.59(3.35-3.83)$ & $2.09(1.91-2.30)$ \\
Lung cancer & $2.15(2.07-2.23)$ & $1.31(1.25-1.39)$ \\
Breast cancer & - & $0.76(0.73-0.79)$ \\
Colorectal cancer & $1.21(1.16-1.27)$ & $0.91(0.86-0.96)$ \\
External causes & $2.67(2.58-2.78)$ & $1.41(1.35-1.48)$ \\
\hline
\end{tabular}

Mortality rate ratio $=\frac{\text { Lowest quartrile }}{\text { Highest quartrile }}$ of socioeconomical status a $95 \%$ confidence interval science, and asked if under the statute "is there room to consider other non-scientific factors in making the major social policy judgment of picking a precise number from a range of scientifically justified values" (Bachmann 2007). Justice Breyer has answered former Administrator Ruckelshaus' question in the affirmative. Indeed, Justice Breyer has recommended the use of comparative health consequences as a context for Standard setting. In doing so, he has indicated that the boundaries of the relevant science for setting a NAAQS are not restricted exclusively to the health effects of the specific pollutant under consideration. This common sense approach has not been evident in many of the recent CASAC deliberations or the policy judgments of the Administration.

\section{Conclusions}

The United States now has nearly a half century of experience of improving air quality under the federal statute, the Clean Air Act, first enacted in 1963. The amendments of 1970, 1977 and 1990 substantially strengthened the CAA. Remarkable progress has been made in improving air quality as assessed using multiple criterion. The establishment of National Ambient Air Quality Standards for criteria pollutants by the EPA and the implementation programs of the individual States have contributed significantly to that success. Every decade from 1970 to the present has seen major actions with regard to the NAAQS and, in general, more stringent Standards. In many instances, Standards have been attained or nearly attained, and then a new more stringent Standard has been introduced. As some have said, we were almost there and then they moved the goal posts, i.e. lowered the Standards.

Now, more than at any time in the past, the policy judgment question must be asked "How low is low enough?" for each of the NAAQS. In my opinion, the guidance of Justice Breyer provides the Administrator broad latitude to make policy judgments consistent with our common goal of enhancing the health of all Americans.

Whatever path is chosen to go forward, there will remain a need for policy judgments informed by the best available scientific information. In creating new scientific information, I urge scientists to think broadly and adopt a strong comparative health benefit orientation. For example, when conducting epidemiological investigations, include multiple air pollutants and other factors, including socio-economic status that may influence the health endpoints being evaluated. Then report on all of the tested associations, not just the results for a single air pollutant. The resulting broader base of knowledge will allow Society to make decisions as to what actions will yield the most improvement in health at the lowest net cost to Society. 
When future Integrated Science Assessment Documents are prepared, I urge that they include information that will help put the reported health effects of the specific pollutant in context. One approach to this might be the development of a generic document that reviews current knowledge on the multiple factors that influence morbidity and mortality from respiratory and cardiovascular disease, the major health outcomes for key criteria pollutants. This information could then be used in multiple Policy Assessment Documents. Both the Integrated Science Assessment and Policy Assessment Documents should more clearly identify and characterize the health effects role of the specific pollutant under consideration as well as the role of co-pollutants and other factors influencing the health outcomes evaluated. Policy Assessment Documents need to include "determinate criterion for drawing lines" as called for by the DC Circuit Court in its American Trucking Associations v. EPA (1999) opinion. These are needed to provide a clearer basis for the Administrator's policy judgments on the level and form of the Standard. These criteria, along with a strong comparative health context, should provide an improved basis for the Administrator's policy decisions.

I also strongly urge the CASAC to focus on the scientific rigor of the scientific content and analyses in the Integrated Science Assessment and Policy Assessment Document, and avoid the temptation of offering policy judgments as to a specific upper-bound level and form of the Standard or what they view as acceptable ranges. If CASAC cannot avoid this temptation to stay out of the "policy judgment thicket," then it needs to be clear as to the specific scientific knowledge that informs their personal policy preferences. CASAC is required to comment to the Administrator under CAA $\S 109(\mathrm{~d})(2)(B)$ "on any new national ambient air quality Standards and revisions of existing criteria or Standards as may be appropriate." However, in offering comments, CASAC needs to very carefully articulate where CASAC scientific interpretations leave off and CASAC policy judgments begin. Moreover, it is important for EPA Administrators to recognize they need not be bound by CASAC's specific policy preferences or range of policy preference outcomes. While the CASAC members are citizens and are certainly entitled, just like any citizen, to have personal preferences as to policy outcomes, CASAC members, acting in that role, should not view themselves as broadly representative of Society at large.

It is critically important that EPA Administrators recognize, as Administrator William Ruckelshaus so clearly did in 1983, that Standards cannot be set solely on science and that the ultimate decision on a level and form of a Standard necessarily reflects policy judgments. Administrators should not seek to find "scientific cover" for these policy judgments in the deliberations offered by CASAC. If this is done, it has the potential to transform the Clean Air Scientific Advisory Committee into a de facto Clean Air Standards Setting Committee, thereby usurping the policy role of the Administrator. I do not think that is consistent with the language of the CAA. The Administrator, as a public official appointed by the President and confirmed by the Senate, is expected to have a broad perspective reflective of all of Society, not just a specific scientific constituency, when making policy judgments in setting National Ambient Air Quality Standards.

Declaration of Interest I have participated, beginning in the mid1970 s, as a member of numerous CASAC Panels providing advice to the EPA Administrator on the setting of the NAAQS for all the criteria pollutants. I served as Chair of CASAC in 1988-1992 when the debate began on shifting the averaging time for the ozone Standard from 1 to $8 \mathrm{~h}$. I served on the CASAC PM Panels that provided advice on the $\mathrm{PM}_{2.5}$ Standards promulgated in 1997 and 2006. I served on the CASAC Ozone Panel that provided advice on the Standard promulgated in 1997. I did not serve on the CASAC Ozone Panel that provided advice to the EPA Administrator on the Standard promulgated in 2008. However, I did follow that activity closely and offered comments to CASAC and EPA on the science informing the Administrator's judgments on the Ozone NAAQS. The views I share in this paper are my own professional views based on three decades of experience participating in the NAAQS setting process. I regularly serve as an advisor to both public and private organizations on air quality issues. This includes the American Petroleum Institute (API) and various companies in the energy and transportation sectors. The views I have expressed are not necessarily those of the API or any organization I advise.

Open Access This article is distributed under the terms of the Creative Commons Attribution Noncommercial License which permits any noncommercial use, distribution, and reproduction in any medium, provided the original author(s) and source are credited.

\section{References}

American Trucking Associations, Inc. vs U.S. Environmental Protection Agency (1999) DC Circuit, May 19, 1999

Bachmann J (2007) Will the circle be unbroken: a history of the U.S. National Ambient Air Quality Standards. J Air Waste Manage Assoc 57:652-697

Berry MA (1984) A method for examining policy implementation: a study of decision-making for the national ambient air quality standards, 1964-1984; U.S. Environmental Protection Agency, Research Triangle Park, NC

Breyer S (1982) Regulation and reform. Harvard University, Cambridge, MA

Breyer S (1993) Breaking the vicious circle: toward effective risk regulation. (Based on 1992 Oliver Wendell Holmes lectures at Harvard Law School). Harvard University, Cambridge, MA

CAA (1963) The Clean Air Act of 1963

CAA (1970) The Clean Air Act amendments of 1970-P.L. 91-04 (December 31, 1970), Plus technical amendments made by P.L. 92-157 (November 18, 1971)

CAA (1977) The Clean Air Act amendments of 1977 
CAA (1990) The Clean Air Act amendments to 1990, Public Law No. 101-549; 104 STAT 2399, 1990

Clinton WJ, President (1993) Executive Order 12866 - regulatory planning and review. Fed Regis 58:51735-51744

Clinton WJ, President (1997) Memorandum for the administrator of the environmental protection agency implementation of revised air quality standards for ozone and particulate matter

Emanuel R (2009) Assistant to the President and Chief of Staff, Memorandum to the Heads of Executive Departments and Agencies. Fed Reg 74(13):4435-4436

Henderson RF (2005) Letter to administrator on particulate matter standard from CASAC Chair, Rogene Henderson to EPA Administrator Stephen Johnson, June 6, 2005

Henderson RF (2006a) Clean air scientific advisory committee recommendations concerning the proposed national ambient air quality standards for particulate matter: Letter from CASAC Chair, Rogene Henderson to EPA Administrator Stephen Johnson, March 21, 2006

Henderson RF (2006b) Clean air scientific advisory committee's review of the agency's draft ozone staff paper: letter from CASAC chair, Rogene Henderson to administrator Stephen Johnson dated October 24, 2006, EPA-CASAC-07-001

Henderson RF, Cowling EB, Crapo JD, Miller FJ, Poirot RL, Speizer FE, Zielinska B (2006c) Clean air scientific advisory committee recommendations concerning the proposed national ambient air quality standards for particulate matter: letter to EPA administrator Stephen L. Johnson, EPA-CASAC-LTR-06-002, March 21, 2006; EPA clean air scientific advisory committee, Washington, $\mathrm{DC}$

Henderson RF (2007) Clean air scientific advisory committee's review of the agency's final ozone staff paper: letter from CASAC Chair, Rogene Henderson to administrator Stephen Johnson dated March 26, 2007, EPA-CASAC-07-002

Henderson RF (2008) Clean air scientific advisory committee recommendations concerning the final rule for the national ambient air quality standards for ozone: letter from CASAC Chair, Rogene Henderson, to EPA Administrator Stephen Johnson, April 7, 2008, EPA-CASAC-08-009

Kennedy D (2005) Risk versus risk. Science 309:2137, 30 September 2005

Library of Congress (1974) A legislative history of the clean air amendments of 1970, Vol. 1; Serial number 93-18: Environmental Policy Decision, Congressional Research Service, Library of Congress, Washington, DC

Martin K (2008) Building on the last ozone NAAQS Review: key policy relevant issues. Presentation to EPA Workshop on Science/ Policy Issues for Next Periodic Review of Ozone NAAQS, October 29, 2008

Martineau R, Novello D (2004) The Clean Air Act handbook. 2nd edition

McClellan RO (1999) Human health risk assessment: a historical overview and alternative paths forward. Inhal Tox 11:477-518

McClellan RO (2007) Comments on national ambient air quality standards for ozone: proposed rule. Submitted on October 9, 2007 to Docket ID No. EPA-HQ-OAR-2005-0172

McClellan RO, Frampton MW, Koutrakis P, McDonnell WF, Moolgavkar S, North DW, Smith AE, Smith RL, Utell MJ (2009) Critical considerations in evaluating scientific evidence of health effects of ambient ozone: a conference report. Inhal Toxicol 21(2):1-36

McClellan RO (2010a) Comments on proposed "Reconsideration" national ambient air quality standard for ozone for presentation at the public meeting. U.S. Environmental Protection Agency, Arlington, VA, February 2, 2010

McClellan RO (2010b) Comments on the proposed "Reconsideration" national ambient air quality standard submitted on March 9, 2007 to the Ozone Docket
McClellan RO (2010c) Hazard and risk assessment and management. In: Jon Ayres G, Roy Harrison M, Maynard R, Gordon Nichols L (Eds.), Textbook of Environmental Medicine Chapter 4 1st Ed., Hodder Education: London, UK pp 59-88

McClellan RO (2011) Written statement for consideration by the clean air scientific advisory committee (CASAC) Ozone review panel at the panel's teleconference meeting on February 18, 2011

New York Times (1997) Clinton sharply tightens air pollution regulations despite concern over costs. NY Times, June 26, 1997

NRDC vs Train (1976) 411F. Supp. 864 (S.D.N.Y.) aff'd 545F.2d 320 (2nd Cir. 1976)

Peacock M (2006) Memorandum from Marcus Peacock, deputy administrator to Dr. George Gray and Bill Wehrun. Process for reviewing the national ambient air quality standards, December 7 , 2006; available at http://www.epa.gov/ttn/naaqs/memo_process for reviewing naaqs.pdf (accepted 2007)

Pedersen WF (1975) Formal records and informal rulemaking. Yale Law J 38:38-88

Rhomberg LR, Goodman JE, Haber LT, Dougson M, Andersen MT, Klaunig JE, Meek B, Price PS, McClellan CSM (2011) Linear low-dose extrapolation for non-cancer health effects is the exception, not the rule. Crit Rev Toxicol 41(1):1-19; available at $\mathrm{http}: / /$ informahealthcare.com/toc/txc/41/1

Samet JM (2011) Clean air scientific advisory committee (CASAC) Response to charge questions on the reconsideration of the 2008 Ozone national ambient air quality standard. EPA-CASAC-11-004. Letter from CASAC Chair, Jonathan M. Samet to Administrator Lisa P. Jackson, March 30, 2011

Steenland K, Hu S, Walker J (2004) All-cause and cause-specific mortality by socioeconomic status among employed persons in 27 U.S. States, 1984-1997. Am J Public Health 94:1037-1042

Taube G (1995) Epidemiology faces its limits. Science 269:164-169

U.S. Environmental Protection Agency (1971) National primary and secondary ambient air quality standards. Fed Reg 36:8186

U.S. Environmental Protection Agency (1977a) Air quality criteria for lead (released December 14, 1977). EPA/600/8-77/017

U.S. Environmental Protection Agency (1977) Lead ambient air quality standard proposal. Fed Regis 42:63076

U.S. Environmental Protection Agency (1978) National ambient air quality standard for lead. Fed Regis 43:46246

U.S. Environmental Protection Agency (1997a) National ambient air quality standard for particulate matter. Final Rule Fed Reg 62:38652-38760, July 18, 1997

U.S. Environmental Protection Agency (1997b) National ambient air quality standard for ozone. Final Rule Fed Reg 62(138):3885538896, July 18, 1997

U.S. Environmental Protection Agency (2004) Air quality for particulate matter (October 2004). 600/P-99/002aF-bF, Washington, DC

U.S. Environmental Protection Agency (2005) Review of the national ambient air quality standards for particulate matter: policy assessment of scientific and technical information (December 2005). EPA-452/R-05-005a, Washington, DC

U.S. Environmental Protection Agency (2006a) National ambient air quality standards for particulate matter: proposed rule. Fed Regis 71:2620-2708

U.S. Environmental Protection Agency (2006b) National ambient air quality standards for particulate matter: final rule. Fed Regis 71:61144-61233

U.S. Environmental Protection Agency (2006c) Air quality criteria for ozone and related photochemical oxidants (Final). Washington, DC: EPA/600/R-05-004aF-cF

U.S. Environmental Protection Agency (2007a) Review of the national ambient air quality standards for ozone: policy assessment of scientific and technical information

U.S. Environmental Protection Agency (2007b) Ozone health risk assessment for selected urban areas, EPA-452/R-07-009 
U.S. Environmental Protection Agency (2007) National ambient air quality standards for ozone: proposed rule 40 CFR part 50 . Fed Regis 72:37818-37919

U.S. Environmental Protection Agency (2007d) Regulatory impact analyses: 2007 Proposed revisions to the national ambient air quality standards for ground-level ozone. Released August 2, 2007. www.epa.gov/ttn/ecas/ria.html\#ria2007

U.S. Environmental Protection Agency (2008) National ambient air quality standards for ozone: final rule 40 CFR parts 50 and 58 . Fed Regis 73:16436-16514

U.S. Environmental Protection Agency (2010a) National ambient air quality standards for ozone. Proposed Rule Fed Reg 75:2938, January 19, 2010

U.S. Environmental Protection Agency (2010b) Primary national ambient air quality standards for nitrogen dioxides: final rule. Fed Reg 75:6474, February 9, 2010

U.S. Environmental Protection Agency (2010c) Primary national ambient air quality standard for sulfur dioxide: final rule. Fed Regis 75:35520-35603, June 22, 2010

U.S. Environmental Protection Agency (2011a) Integrated science assessment for ozone and related photochemical oxidants (First External Review Draft). U.S. Environmental Protection Agency, Washington, DC, EPA/600/R-10/076A
U.S. Environmental Protection Agency (2011b) Notification of Public Teleconference of the Clean Air Scientific Advisory Committee (CASAC): Ozone Review Panel for Reconsideration of the 2008 National Ambient Air Quality Standard. Fed Reg 76:10895, February 28, 2011

Wegman LN (2011) Solicitation of CASAC Advice on EPA's Reconsideration of the 2008 Primary Ozone National Ambient Air Quality Standard. Letter to Holly Stallworth, Designated Federal Official, CASAC, January 25, 2011

White RH, Cote I, Zeise L, Fox M, Dominici F, Burke TA, White PD, Hattis DB, Samet JM (2009) State-of-the-Science Workshop Report: Issues and Approaches in Low Dose-Response Extrapolation for Environmental Health Risk Assessment. Available at: http://www.ehponline.org/members/2008/ 1150211502.pdf. Environmental Health Perspectives 117(2): doi:10.1289/ehp.11502

Whitman vs American Trucking Associations (2001) 531 U.S. 457, 121 S. Ct. 903149L. Ed. 2d1

Wolff GT (1996) Letter to Carol M. Browner, U.S. Environmental Protection Agency Administrator. closure on draft Office of Air Quality Planning and Standards (OAPQS Staff Paper) (Review of the National Ambient Air Quality Standards for Particulate Matter: Policy Assessment of Science and Technical Information) 